\title{
MANAGING MILLENNIALS AS OUTSOURCED INFORMATION TECHNOLOGY PROFESSIONALS: A SYSTEMATIC REVIEW
}

\author{
Tiago Jacob Fernandes França ${ }^{1}$, Henrique São Mamede ${ }^{2}$ and Vítor Duarte dos Santos ${ }^{3}$ \\ ${ }^{1}$ Instituto Superior Técnico, Universidade Aberta, 1250-100 Lisboa, Portugal \\ ${ }^{2}$ Universidade Aberta, INESC TEC, 1269-001 Lisboa, Portugal \\ ${ }^{3}$ Universidade Nova - IMS, 1070-312 Lisboa, Portugal
}

\begin{abstract}
The Information Technology Outsourcing (ITO) model has been a trend in recent decades, becoming the dominant trend in contemporary outsourcing scenario. Millennials will soon, globally, be the majority of the workforce, having a particular way of relating to organizations and to work itself as no previous generation did. Information technologies continue to employ more and more human resources, having an increasing demand and a shortage of competent resources. It is therefore important to rethink current Human Resources Management (HRM) models and design a new strategic and appropriate model to accommodate and anticipate the needs of managers and monitor the development of this generation as Information Technology (IT) professionals. The intersection and analysis of the Information and Communications Technologies (ICT), millennials, Human Resource Management, outsourcing and organizations is the objective of this study, to identify the most relevant articles regarding millennials as outsourced IT professionals.
\end{abstract}

\section{KEYWORDS}

Organizations, ICT, Outsourcing, HRM, Millennials, ITO

\section{INTRODUCTION}

A systematic review was performed based on a search of the literature where a total of 22 articles were retrieved. The combined articles report the context of millennials as IT professionals thus contributing to enhance our knowledge of the subject, especially being such a specific perspective, adding new insights on the matter. The following five dimensions, as seen in figure 1, forms an interconnected structure, essential to understand the specific context of millennials as outsourced Information Technology (IT) professionals. The five dimensions are born from Organizations, including the Information and Communications Technology (ICT), which often uses the Outsourcing model, where the Human Resources Management (HRM) plays a fundamental role, especially in Millennials, the target group of this study.

As providers of opportunities and managers of both professional and social development of their human resources, organizations are considered to be the first dimension, encompassing the other four dimensions, where millennials are so different from those of one and two generations ago (Thompson and Gregory, 2012). The second dimension, the ICT, an area in constant development and increasingly strategic for any organization that wants to evolve and obtain a competitive advantage (Deloitte, 2019). Outsourcing is the third dimension, increasingly valued and used, especially in the area of information technologies (Deloitte, 2019). HRM, the fourth dimension, is fundamental to the management and development process of millennials. "Working with the human being means developing it" (Drucker, 1986). Finally, millennials themselves, the target population of this study, are considered the fifth dimension. 


\begin{tabular}{|l|l|l|}
\hline $1^{\text {st }}$ Dimension & \multicolumn{2}{l|}{ Organizations } \\
\hline $2^{\text {nd }}$ Dimension & ICT & \\
\hline $3^{\text {rd }}$ Dimension & & Outsourcing \\
\hline $4^{\text {th }}$ Dimension & HRM \\
\hline $5^{\text {th }}$ Dimension & Millennials \\
\hline
\end{tabular}

Figure 1. The five dimensions

The reason for this study is due to the urgency of the generation, for being current and because it will soon be the largest workforce in the world. Therefore, it is urgent to understand them, within organizations, and in a context in constant evolution and mutation such as ICT, where the hiring models - due to the growth and the particularities of the area - are very permeable to subcontract or outsource services. The convergence of digital transformation and the impact of changes in the technological, sociological, psychological and management dimensions merge in the millennials, shaping them by their relationship with technology (Elmore and Cathy, 2009), where everything is relational, of associated intelligence and collective, with effectively global behaviors.

The Information Technology Outsourcing (ITO) model in organizations is becoming a constant (Deloitte, 2019) and has been a trend in recent decades, becoming the dominant trend in the contemporary outsourcing scenario. Inserting themselves in the transition to the new century, highly technological and global, millennials are the first truly digital generation, not only are they interested in technology, they are also specialists (Holt, 2012).

According to Schawbel (2012) millennials will soon, globally, be the majority of the workforce. Thus, to accommodate and anticipate the needs of managers and monitor the management of millennials as outsourced IT professionals, it is understood that it is necessary to rethink current HRM processes and design new ones, as the psychological and sociological needs of millennials are very specific and different from previous generations, to which organizations are accustomed. As such, organizations must evolve and follow the reality of this generation, considering the relevant dimensions which require an increasingly strategic attention, in order to be successful in this organizational dynamic.

We intend to obtain a selection of articles related to outsourcing, organizational management, human resources management, millennials and the area of information technologies, so it is needed to understand the state of the art with regard to these themes, relating the information where it is relevant. The target population of this study are millennials as outsourced IT professionals, considering the processes that address specific questions about the management of human resources. The results must be related to the factors of importance for outsourcing in the areas of information technology and the context will be the management of human resources of information technologies, specifically regarding millennials. The research question was "What is the management process of millennials as outsourced information technology professionals?". The following chapters will describe the literature review, method, results and conclusions.

\section{LITERATURE REVIEW}

This Systematic Literature Review was carried out following the proposal by Kitchenham (2004) aiming to present a correct assessment on the research topic using a reliable, rigorous and auditable methodology. The first step when developing a Review Protocol is to define the query string that will be used to search the defined data sources, in order to find the maximum number of studies on the subject in question. Several attempts were made with different query strings until finding a more suitable one, according to the keywords used in table 1. The defined query string was: ("millennials" OR "Generation Y") AND ("human resources management" OR "HRM") AND ("information technology outsourcing" OR "ITO").

Table 1. Keywords and synonyms

\begin{tabular}{ll}
\hline Keyword & Synonyms \\
\hline Human Resources Management & HRM \\
Information Technology Outsourcing & ITO \\
Millennials & Generation Y \\
\hline
\end{tabular}


The search process was based on a digital search, accessing the information sources listed in table 2 .

Table 2. Information sources

\begin{tabular}{ll}
\hline Information Sources & Address \\
\hline Crossref & https://www.crossref.org \\
Google Scholar & https://scholar.google.com \\
Scopus & https://www.scopus.com \\
\hline
\end{tabular}

Inclusion and exclusion criteria were defined and listed in table 3, in order to be applied to collected documents based on the previous step.

Table 3. Inclusion and exclusion criteria

\begin{tabular}{ll}
\hline Inclusion Criteria & Exclusion Criteria \\
\hline Scientific Documents & Incomplete articles; \\
& $\begin{array}{l}\text { Duplicate articles; } \\
\text { Publications prior to 2000; } \\
\text { Lack of access to the article; } \\
\text { Languages different from English or Portuguese. }\end{array}$ \\
& Themes not relevant to this investigation. \\
Thesis & \\
Reference Consultant Publications & Themes not relevant to this investigation. \\
\hline
\end{tabular}

Although there were no intentions for the study to be biased in any way, it should be mentioned that it has limitations, specifically over the dependency on the selected keywords, the selected databases and in the fact that literature and publications written in other languages than English and Portuguese were excluded. Also, the inclusion and exclusion criteria have a relevant impact on the chosen articles and therefore on the included articles in this study. The exclusion criteria for publications prior to 2000 was based on the fact that this study is centered on millennials, so, studies from the year in which millennials begin their professional career were considered to be more relevant.

Only three databases were used, and for that reason we may be excluding relevant articles, but we believe that among these sources we are searching the vast majority of the relevant documents. These sources provide a simple way to search extensively over academic literature, articles, thesis, books, abstracts, academic editors, professional societies, online repositories and universities, where it is possible to search across different disciplines. In addition to the collected articles through this protocol, other relevant documents were also identified, either because they are references used in the researched documents or because they are the result of separate research on the topics in question, documents that are however included in this study and that are an integral part of the bibliographic reference.

\subsection{Method}

In this section we describe the review, in which we select primary studies and extract data using the review protocol developed in the previous step. After applying the defined query string, a total of 559 results were obtained. The records identified by data source are distributed as follows: Scopus $(\mathrm{n}=104)$, Google Scholar $(\mathrm{n}=222)$ and Crossref $(\mathrm{n}=233)$, as shown in figure 2 .

After applying the criteria defined in the previous section, the number of documents was reduced to a set of 35. In addition, a quality assessment was carried out on them, consisting of the following questions, which helped selecting the articles to include in this study:

$\circ \quad$ Is the article relevant to answer the research question?

- Does the article focus on millennials as the subject of the study?

- Does the article refer to information systems (technology, people and processes)?

- Does the article refer to ITO as a research objective, motivation or question?

- Does the article refer to how organizations manage human resources in order to provide the information needed to achieve their goals? 


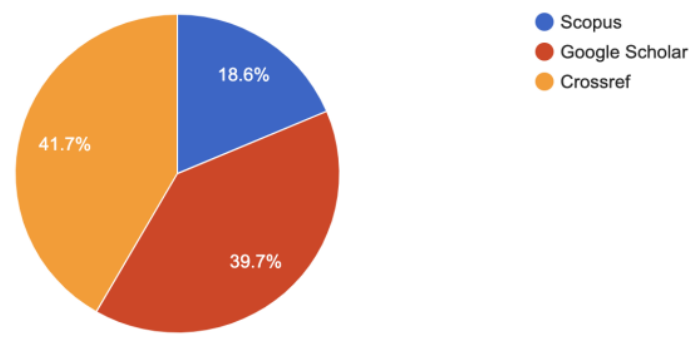

Figure 2. Article distribution by information sources

Table 4 shows the possible answers and respective scores for the quality assessment questions. The answers were limited to "Yes", "Partially" and "No", and for each one, a score was assigned, determining the definitive inclusion or exclusion of articles in the study.

Table 4. Answer score for quality assessment questions

\begin{tabular}{ll}
\hline Answer & Score \\
\hline Yes & 1.0 \\
Partially & 0.75 \\
No & 0 \\
\hline
\end{tabular}

The maximum score is 5.0, a calculation based on the number of possible answers with the highest score, while the minimum score for electing an article was set at 2.5. There are articles in which the content does not answer all the proposed questions, but it is relevant enough to be included in the study, therefore, when defining the minimum eligibility score, it will be necessary to have at least one answer whose result is "Yes" and two answers with "Partially".
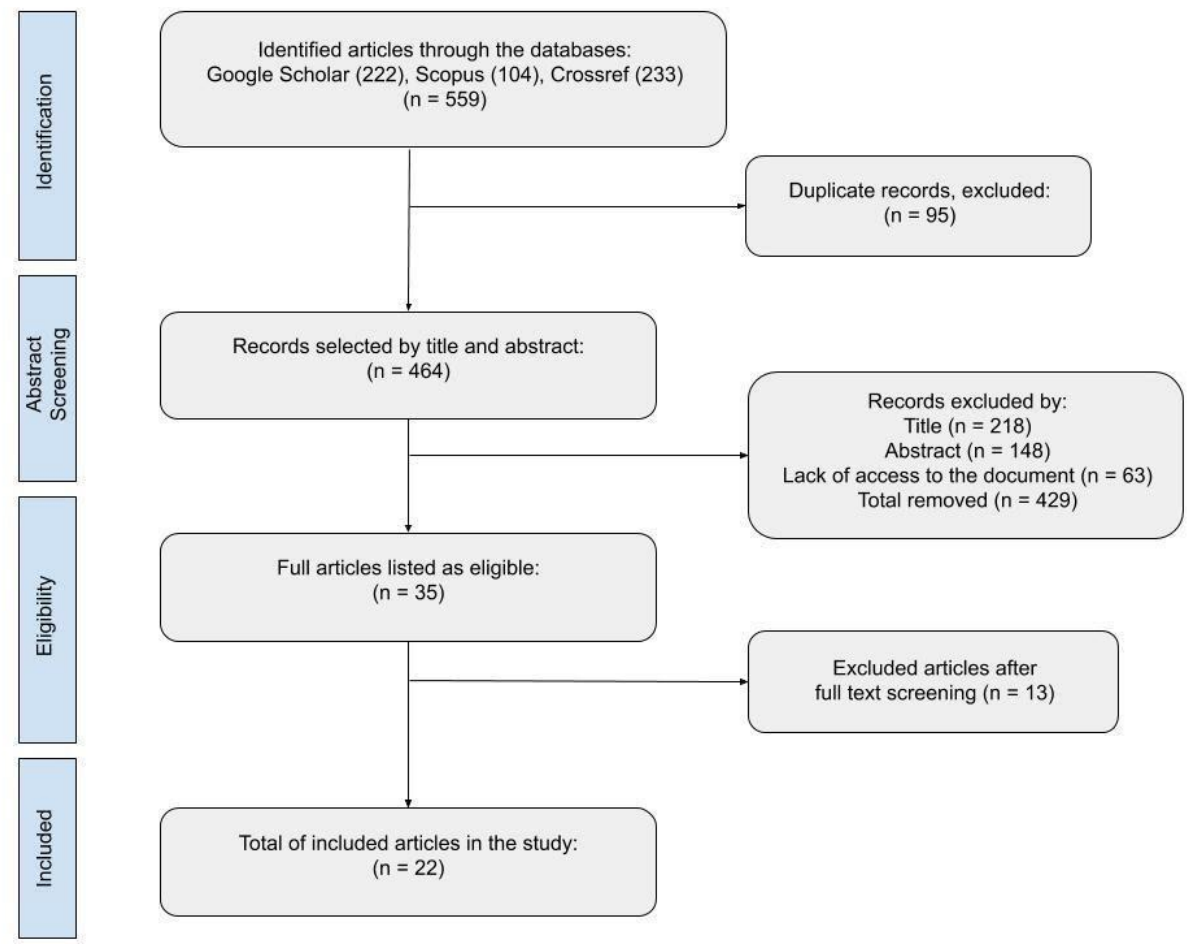

Figure 3. Article selection flowchart

The total number of records identified were $(n=559)$, and were removed $(n=95)$ identified as duplicates. Of the remaining articles $(n=464)$, several articles were excluded by title and abstract, in the following proportion: excluded by Title $(n=218)$, excluded by Abstract $(n=148)$. It was not possible to access some of 
the articles, due to unavailability of the source or because they had limited access, which excluded them $(n=63)$. A total of $(n=429)$ articles were removed.

There were $(n=39)$ articles eligible to be included in the investigation. After reading these articles in full and scoring according to the quality assessment answers, some articles were still excluded $(n=13)$. The total articles included in the investigation are $(\mathrm{n}=22)$ as seen in figure 3 .

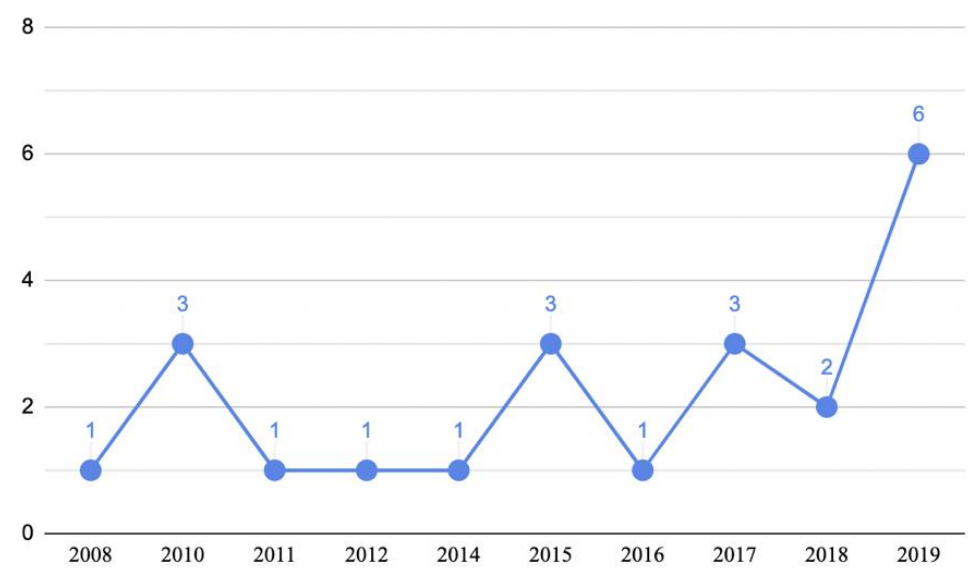

Figure 4. Number of included articles by year of publication

The selected articles were published between 2008 and 2019, as shown in figure 4. Table 5 shows the article's authors, the dimension to which it relates to, the year of publication and the score obtained. The included articles were annotated in order to show its relevance, from a critical perspective and in the light of the research question.

Table 5. Selected articles list

\begin{tabular}{llll}
\hline Author & Dimension & Year & Score \\
\hline Conde, S. R. & Outsourcing | Organization & 2019 & 4.0 \\
Soares, L. P. M & Millennials | HRM & 2019 & 3.0 \\
Azmi, F. & HRM | ICT & 2019 & 3.25 \\
Hassan, M. et al. & Millennials | HRM & 2019 & 3.5 \\
Solomon, C., \& Van Coller-Peter, S. & Millennials | Organization | HRM & 2019 & 3.0 \\
Thite, M. & HRM | ICT & 2018 & 3.25 \\
Souto, C.P. & Millennials | Organization | HRM & 2018 & 3.25 \\
Lioliou, E., \& Willcocks, L. P. & ICT | Outsourcing & 2018 & 2.75 \\
Nasir, S. Z. & HRM | ICT & 2017 & 2.75 \\
Cassell, S. K. & Millennials | HRM & 2017 & 3.5 \\
Bartz, D. et al. & Millennials | Organization | HRM & 2017 & 2.5 \\
Marler, J. H., \& Parry, E. & HRM | ICT & 2016 & 3.0 \\
Galetić, L. & Millennials | HRM & 2015 & 2.5 \\
Özçelik, G. & Millennials | Organization & 2015 & 3.0 \\
Valente, A. \& Correia, I. & ICT & 2015 & 4.0 \\
Jerome, A. et al. & Millennials | Organization & 2014 & 2.5 \\
Thompson, C., \& Gregory, J. & Millennials | Organization & 2012 & 3.25 \\
Smyrl, B. J. & Millennials | HRM & 2011 & 2.75 \\
Hershatter, A., \& Epstein, M. & Millennials | Organization & 2010 & 3.0 \\
Myers, K. K., \& Sadaghiani, K. & Millennials | Organization & 2010 & 3.0 \\
Levenson, A. R. & Millennials | Organization & 2010 & 2.75 \\
Westlund, S. & Organization | ICT & 2008 & 3.0 \\
\hline
\end{tabular}




\subsection{Results}

Organizations that do not attract a vital core of millennial employees will be lacking in competitive vigor (Jerome, 2014) so, in order for organizations to attract millennials, it is necessary to understand their expectations and contribution to the success of organizations.

There is a lack of hundreds of thousands of qualified professionals in the digital area (Valente and Correia, 2015) suggesting that education and training entities, having the scope for adaptation and innovation, should connect with organizations in the sector renewing training references, providing internships, ensuring access to business training.

The strengths and opportunities of using human resources outsourcing services outweighs the weaknesses and threats (Conde, 2019) sustaining the fact that outsourcing is clearly beneficial for organizations as it allows bringing specialized knowledge. According to Lioliou and Willcocks (2018) selective outsourcing carried out by different suppliers with short-term contracts is the scenario most likely to generate positive results, as it has been the trend for the past 25 years for organizations to outsource through different suppliers, becoming the dominant trend in the contemporary outsourcing scenario.

The retention of young employees has become an increasing and global problem and remains unresolved, so it is necessary for organizations to focus on leadership, to promote innovation, to recognize employees as an important factor in the organization (Hassan, 2019) and with a leadership capable of promoting the balance between personal and professional life.

Perhaps the most important factor for millennials is to feel valued and supported by their direct supervisor (Cassell, 2017) revealing that the main elements identified for creating feelings of support are organizational policies that promote development opportunities, flexible options for work and balance between professional and personal life. Bartz (2017) speaks of an environment for millennials in which they can be and give their best, through processes of feedback and coaching, supported by their supervisors.

According to Solomon and Van Coller-Peter (2019) coaching is a viable strategy for organizations to involve and retain their millennial professionals, particularly with regard to career development, as millennials highly value the balance between professional and personal life. Human resource managers started designing complex strategies for the organization, including finding balance between personal and professional life (Nasir, 2017) and Soares (2019) verified the positive impact of performance evaluation on the career of millennial professionals, namely in the search for knowledge, in the development of skills, in the knowledge of new technologies, in self-evaluation and in influencing decision making.

According to Westlund (2008) organizations should develop cultures that stimulate creativity, autonomy, motivation and organizational commitment, progressively challenging and creating opportunities so its employees can learn new technologies and recognize the achievements of the teams. Souto (2018) concluded that the work values most valued by millennials are those of development, where they intend to have the opportunity to develop their skills, have adequate training and be able to work on motivating projects. They also value the opportunity to be part of a team, to have a manager who gives constructive feedback, where the work environment is dynamic, fun and allows for constant social interaction.

Galetić (2015) reveals that millennials give more importance to non-material rewards and shows that millennials are not necessarily a homogeneous group, recommending that human resource managers should adapt reward strategies to individual characteristics, emphasizing that young millennials with work experience greatly favor job training, teamwork and participation in decision-making.

For Thite (2018) the focus of digital human resource management must be on a digital workforce, agile and focused on innovation, in a digital workplace characterized by a learning mentality. Both the digital transformation and the human resource managers generate a circular impact in the strategic role of the HRM over the organization (Marler and Parry, 2015), also Azmi (2019) explains how the interaction between information technologies and HR brought a new culture of information, through instantaneity, interactivity, informality and intangibility where organizations take advantage of the experiences created by social networks using their power to effectively manage human resources for the acquisition, management and retention of talent. Ozcelik (2015) states that employees must receive value propositions through effective communication, especially millennials who develop feelings of loyalty through the opportunity to work from home or have flexible hours.

Thompson and Gregory (2012) refer that organizations consider common stereotypes of millennial employees in the educational, political, economic and social contexts present in their formative years suggesting that management style can be the key to successfully leveraging the talents of millennials in organizations. Hershatter and Epstein (2010) say millennials are concerned with authenticity and institutional values because they rely on work to promote change, where their skills with technology allow them to access 
information easily and creatively and to think and function in a world without borders, being oriented to people and organizations, thus facilitating the process of involvement and acculturation.

Smyrl (2011) describes millennial's main values as optimistic, reliable, civic and achievement oriented and according to Myers and Sadaghiani (2010) millennials work well as a team, are motivated to create an impact on their organizations, favor open and frequent communication with their supervisors and are at ease with information technologies. Real change is probably much more incremental and gradual from one generation to the next so organizations should be aware whether this change is significant as a characteristic that defines an entire generation knowing when a gradual change becomes a turning point (Levenson, 2010).

\section{CONCLUSION}

There are a growing number of studies concerning millennials and their profile definition is consistent. Millennials now make up a large percentage of the global workforce and will soon be the majority. We know that millennials have a particular way of relating to organizations and to work itself, as no previous generation has done. ICT continues to employ even more human resources, but there is an increasing demand and a shortage of competent resources while the ITO model has become the dominant trend in the contemporary outsourcing scenario.

It is understood that people management will represent one of the greatest challenges for organizations, not only due to multigenerational issues, where organizations will have to find the best practices to simultaneously maintain different generations with different satisfaction factors, but also to learn how to understand these generational groups and enabling them to do their best, together and in line with the organization's strategy. Technology, globalization, demographics and other factors influence organizational structures and cultures. Nowadays organizations deal with the reality of the scarcity of competent resources, managing people through change, in an attempt to create an effective workforce.

We know that millennial professionals are attracted to organizations by a distinct set of advantages, valuing the organization's culture and flexibility in determining their own ways of working and showing their views through open communication channels. After joining the organization, they seek support and guidance through mentors and to keep them in the organization they demand balance between personal and professional life, they want to be constantly learning and to strengthen their knowledge.

Any processes suitable for millennials management will have to respond to their needs and integrate them with the needs and reality of the organizations. The author believes this study findings contribute to add knowledge mainly to organizations and human resources management, as we can perceive millennial's profile as outsourced IT professionals allowing organizations to better adapt to them.

Further research should be taken in order to create new or enhance existing organizational management processes highlighting millennials as outsourced IT professionals, considering all the environment it relates to, like multigenerational issues, incorporating technology in the professional relation with millennials and considering new work habits like remote working.

\section{REFERENCES}

Azmi, F. (2019). Technology and HRM. In Strategic Human Resource Management: Text and Cases (pp. 80-108). Cambridge: Cambridge University Press. doi:10.1017/9781108687058.004

Bartz, D. et al. (2017). Maximizing the Human Capital of Millennials Through Supervisors Using Performance Management. International Journal of Management, Business, and Administration, Vol.20(No.1).

Cassell, S. K. (2017). HRM Solutions for Retaining Millennials in Western Societies. Mediterranean Journal of Social Sciences, Vol.8(No.5).

Conde, S. R. (2019). Outsourcing Human Resources: a Practical View. https://hdl.handle.net/10216/123277

Deloitte. (2019). Outsourcing and Shared Services 2019-2023. http://outsourcing-outlook.com/assets/pdf/Deloitte-DOCWhitepaper_outsourcing-and-shared-services2019-2023.pdf

Drucker, P. F. (1986). The Frontiers of Management (1st ed.). New York, EUA: Dutton Adult.

Elmore, T., \& Cathy, D. (2009). Generation iY: Our Last Chance to Save Their Future. Atlanta, GA: Poet Gardener Publishing.

Galetić, L. (2015). Adapting reward strategies to millennials pay preferences. http://bib.irb.hr/datoteka/790664.Adapting_reward_strategies_to_millennials_pay_preferences.pdf 
Hassan, M. et al. (2019). Redesigning the retention strategy against the emerging turnover of generation Y: Revisiting the long-standing problems from the $20^{\text {th }}$ to the $21^{\text {st }}$ century. International Journal of Entrepreneurship, Vol.23(No.2).

Hershatter, A., \& Epstein, M. (2010). Millennials and the World of Work: An Organization and Management Perspective. Journal of Business and Psychology, Vol.25(No.2), 211-223. https://doi.org/10.1007/s10869-010-9160-y

Holt, S. et al. (2012). Bracing for the Millennial Workforce: Looking for Ways to Inspire Generation Y. Journal of Leadership, Accountability and Ethics, Vol.9(No.6), 81-93. http://www.nabusinesspress.com/JLAE/MarquesJ_Web9_6_.pdf

Jerome, A. et al. (2014). Millennials in the Workforce: Gen Y Workplace Strategies for the Next Century. E-Journal of Social \& Behavioral Research in Business, Vol. 5(No.1), 1-12.

Kitchenham, B. (2004). Procedures for Performing Systematic Reviews (Keele University Technical Report TR/SE0401).

Levenson, A. R. (2010). Millennials and the World of Work: An Economist's Perspective. Journal of Business and Psychology, Vol.25(No.2), 257-264. https://doi.org/10.1007/s10869-010-9170-9

Lioliou, E., \& Willcocks, L. P. (2018). The Study of Information Technology Outsourcing. Global Outsourcing Discourse, 21-57. https://doi.org/10.1007/978-3-319-74045-4_2

Marler, J. H., \& Parry, E. (2015). Human resource management, strategic involvement and e-HRM technology. The International Journal of Human Resource Management, Vol.27(No.19), 2233-2253. https://doi.org/10.1080/09585192.2015.1091980

Myers, K. K., \& Sadaghiani, K. (2010). Millennials in the Workplace: A Communication Perspective on Millennials' Organizational Relationships and Performance. Journal of Business and Psychology, Vol.25(No.2), $225-238$. https://doi.org/10.1007/s10869-010-9172-7

Nasir, S. Z. (2017). Emerging Challenges of HRM in the 21st Century: A Theoretical Analysis. International Journal of Academic Research in Business and Social Sciences, Vol.7(No.3). https://doi.org/10.6007/JJARBSS/v7-i3/2727

Ozcelik, G. (2015). Engagement and Retention of the Millennial Generation in the Workplace through Internal Branding. International Journal of Business and Management, Vol.10(No.3). https://doi.org/10.5539/ijbm.v10n3p99

Schawbel, D. (2012). Millennials vs. Baby Boomers: Who Would You Rather Hire? Accessed on February 2, 2020, https://business.time.com/2012/03/29/millennials-vs-baby-boomers-who-would-you-rather-hire/

Smyrl, B. J. (2011). Leading a Multi-Generational Workforce: Understanding Generational Differences for Effective Communication. College of Professional Studies Professional Projects. Paper 28.

Soares, L. P. M. (2019). O impacto da avaliação de desempenho na carreira profissional da geração Y. http://hdl.handle.net/1822/61103

Solomon, C., \& Van Coller-Peter, S. (2019). How coaching aligns the psychological contract between the young millennial professional and the organisation. SA Journal of Human Resource Management, 17. https://doi.org/10.4102/sajhrm.v17i0.1146

Souto, C. P. (2018). Employer Branding: A Importância dos Work Values na atração de colaboradores da Geração Y. https://hdl.handle.net/10216/116794

Thite, M. (2018). Electronic/Digital HRM: A Primer. (M. Thite, Ed.) (1st ed.). London: Routledge.

Thompson, C., \& Gregory, J. (2012). Managing Millennials: A framework for improving attraction, motivation, and retention. The Psychologist-Manager Journal, $237-246$. https://doi.org/10.1080/10887156.2012.730444

Valente, A., \& Correia, I. (2015). Mapeamento da Oferta de Educação e Formação em TICE em Portugal. Portugal: Fundação para Ciência e Tecnologia (FCT) e Fundação Calouste Gulbenkian (FCG).

Westlund, S. (2008). Retaining talent: Assessing job satisfaction facets most significantly related to software developer turnover intentions. International Journal of Information Technology and Management - IJITM. 19. 